\title{
Projeto de Cooperação CAPES-COFECUB: União Européia e Mercosul: Convergências e Divergências ent're Parceiros em TransformaÇão
}

\section{Pesquisadores Responsáveis: Martha Lucía Olivar Jiménez (PPGDir.-UFRGS) Catherine Flaesch-Mougin (Univ. de Rennes I - CEDRE)}

\section{Caracterização do problema e plano de trabalho}

A análise comparativa das duas experiências integracionistas será realizada fundamentalmente em dois níveis:

\section{I-Estrutura interna: aspectos institucionais e contenciosos}

Os dois agrupamentos regionais encontram-se em diferentes graus de integração e fazem uso de diferentes métodos. Os desenvolvimentos recentes do Mercosul e da União Européia reavivam o interesse por uma comparação. Esta se focalizará sobre alguns pontos em especial, nos quais as contribuições normativas e jurisprudenciais mostram-se particularmente importantes.

O surgimento de ordenamentos jurídicos autônomos caracterizados pela presença de fontes próprias, uma hierarquia de normas, sua invocabilidade por particulares e a existência de um controle jurisdicional. Se a ordem jurídica comunitária está bem estabelecida, a da União, em contrapartida, na falta da adoção de um tratado constitucional, está meramente esboçada - tarefa para que a Corte vem contribuindo (ver caso Pupino de 16 de Junho de 2005 no qual emergem os princípios de um direito da União). A ordem jurídica do MERCOSUL apresenta-se bastante precária, contudo, esforços pela sua consolidação em nível institucional, assim como nas ordens jurídicas nacionais, devem ser constatados nos últimos cinco anos. Desde 18 de fevereiro de 2002 foi criado um Tribunal Permanente de Revisão, tal vez um dos primeiros passos para a constituição futura de um sistema jurisdicional supranacional. A comparação com os instrumentos disponíveis no âmbito da Corte de Justiça da União é, assim, bem interessante. $O$ Tribunal pode converter-se num dos motores de processo de integração no Cone Sul.

Os princípios fundadores dos dois processos de integração e sua concretização: democracia, respeito aos direitos do homem, estado de direito, solidariedade. É interessante constatar que o respeito dos Direitos Humanos constitui uma condição 
essencial para a adesão de um Estado em qualquer uma destas organizações. A Cláusula dos Direitos Fundamentais é parte integrante do "acervo comunitário" e do "acervo mercosulino". De outra parte, a transformação da Comissão Parlamentar Conjunta no Parlamento do Mercosul representa uma evolução significativa do ponto de vista da defesa da democracia. Neste aspecto um certo mimetismo institucional com o Parlamento Europeu pode ser verificado.

A personalidade jurídica: entre reconhecimento expresso (Mercosul/ Comunidades) ou implícito (União), e desenvolvimentos práticos nas relações internacionais das duas entidades (acordos mistos que requerem a presença dos Estados membros, adesão da União e do Mercosul a outras organizações internacionais).

A ampliação dos processos de pré-adesão: a União Européia e o Mercosul e seus respectivos processos de alargamento; uma comparação entre os dois processos é oportuna do ponto de vista dos critérios de adesão, das exigências em matéria de retomada do acervo de cada uma, do status dos futuros membros em relação às instituições das quais farão parte... Se a questão tem sido freqüentemente analisada no âmbito comunitário europeu não tem sido assim no Mercosul, mas a proposta de adesão de Venezuela obrigou a regulamentar a questão. A análise comparativa dos procedimentos permitira determinar os problemas e perspectivas que se apresentam no Mercosul.

\section{Grupo de trabalho sobre o Tema:}

Professores de Rennes: Catherine Flaesch-Mougin, Murielle Le Barbier-Le Bris, Chritine Delcourt, Nathalie Hervé-Fournereau, Susana Arrosa Soares.

Professores de Porto Alegre: Martha Lucía Olivar Jimenez, Vera Maria Jacob de Fradera.

Doutorandos de Rennes: Sylvain Laurent, Cécile Rapoport, Isabelle Bosse-Platière.

Doutorandos de Porto Alegre: Priscilla Abella Ethur, Ricardo Rocha de Vasconcellos (post-doc, Université Fédérale de Pelotas).

\section{II - Relação União Européia/Mercosul}

O acordo-marco que vincula os dois grupos regionais é histórico. Trata-se efetivamente do primeiro acordo entre duas uniões alfandegárias, ainda que o Mercosul seja uma união alfandegária imperfeita. O objetivo essencial será estudar os obstáculos que se apresentam no âmbito das negociações, assim como as implicações jurídicas da parceria que resultaria da implementação do acordo.

Estudo do direito convencional entre a Comunidade Européia e o Mercosul: Acordo marco inter-regional CE/MERCOSUL, acordos bilaterais de "terceira geração" entre a CE e os Estados membros do Mercosul, acordos setoriais (cooperação científica...). Programas unilaterais cujo objetivo é o de complementar ou prolongar certas áreas dos acordos (SPG). 
Perspectivas abertas pela associação. Será interessante analisar comparativamente os acordos de "associação" CE/México e CE/Chile, na medida em que a União pretende uniformizar suas relações com o conjunto de países e agrupamentos regionais do subcontinente latinoamericano. Em esta perspectiva foram apresentadas na Cimera de Viena, em maio de 2006, as negociações com os países do Mercado Comum Centroamericano.

Situação e razões do bloqueio das negociações. As divergências entre parceiros concentram-se na proposição européia à questão agrícola julgada insatisfatória pelo Mercosul. Os europeus procuram obter uma maior abertura do setor de serviços e mercados públicos.

Articulação com a OMC a respeito dos critérios colocados pelo artigo XXIV do GATT, relativo às integrações regionais (prazo da realização da zona de livre câmbio, nível da liberalização dos intercâmbios entre os dois parceiros comerciais); estudo do alcance do futuro acordo (o desenvolvimento de uma estratégia "OMC plus" nas áreas não regulamentadas pela "legislação $O M C$ " como investimentos, concorrência, transportes marítimos, etc.).

Impacto potencial da associação: de dois pontos de vista: interno: criação de um direito de associação, estatuto e impacto nos ordenamentos jurídicos das partes; externo: capacidade dos parceiros de prolongar sua parceria "estratégica regional" dentro dos limites internacionais e de promover normas que "humanizem" a globalização; o impacto da homogeneização das relações euro-latino-americanas na estruturação da região.

\section{Grupo de trabalho sobre o Tema:}

Professores de Rennes: Joël Lebullenger, Alexandra Bellayer-Roille, Danielle CharlesLe Bihan.

Professores de Porto Alegre: Valesca Raizer Borges, Heloisa Conceição Machado Da Silva, Raul Rojo.

Doutorandos de Rennes: Jamel Kasmi, Alan Hervé, Clara Avril, Sébastien Roset.

Doutorandos de Porto Alegre: Maria Cristina D'Omellas, Kelly Cristina Bruch.

\section{Antecedentes de cooperação com a parte francesa}

O CEDRE, tendo empreendido a constituição de uma rede internacional sobre o direito da integração (abordagem comparada dos processos de integração regional - na América Latina, na Ásia, na zona "África-Caribe-Pacífico" e no Mediterrâneo assim como o exame das relações exteriores da União Européia com seus grupamentos), deseja estabelecer e reforçar cooperações institucionais com os parceiros latino-americanos, liderados pelo Brasil.

Com efeito, o CEDRE estabeleceu fora da União Européia relações de colaboração com a Escola doutoral regional da África Ocidental, localizada no Senegal (Universidade Cheik Anta Diop de Dakar), com o Centro de Estudos Europeus e de direito da integração de Ouagadougou, em Burkina Faso, com a Universidade Federal 
do Rio Grande do Sul, assim como contatos com a Universidade de Ottawa (Canadá), com o Líbano, com a Turquia. No âmbito da União Européia, o CEDRE colabora com os numerosos centros universitários Jean Monnet e mantém laços particularmente privilegiados com o Instituto Europeu de Gand e, no além-mar com o Centro de Pesquisas sobre os Poderes Locais no Caribe - CRPLC UMR CNRS - Universidade das Antilhas, Guiana.

São organizados reiteradamente congressos internacionais que permitam manter ativa essa rede. O primeiro aconteceu em 1996, em Rennes, e tratou do tema "A parceria entre a União Européia e as Américas: o livre-comércio em questão" (escritos publicados sob a direção de Joël LEBULLENGER e Catherine FLAESCH-MOUGIN, publicado por PUF, 1999, 376 páginas); o segundo, organizado conjuntamente pelo CEDRE e pelo CRPLC, ocorreu na Faculdade de Direito da Martinica, nos dias 9 e 10 de Novembro de 2000, e teve como tema "As relações entre a União Européia e os países ACP segundo o modelo de Lomé - qual parceira?" (a ser publicado pela editora Bruylant, Bruxelas, em 2006). Dele participaram membros das duas equipes CNRS, assim como os professores Luc Marius IBRIGA da Universidade de Ouagadougou (Burkina Faso) e Martha Lucia OLIVAR JIMENEZ da Universidade Federal do Rio Grande do Sul (Brasil). O contato pessoal com essa última, retomado num congresso organizado pela European Community Studies Association (ECSA WORLD), em Bruxelas, nos dias 19 e 20 de setembro de 1996 ("A União Européia em um mundo em transformação"), após uma visita efetuada ao CEDRE, foi o prelúdio à realização de uma missão ao Brasil empreendida pelos professores $\mathrm{J}$. LEBULLENGER e C. FLAESCH-MOUGIN dos dias 19 de junho de 2000 a 3 de julho do mesmo ano. As professoras M.L. OLIVAR JIMENEZ e Véra Jacob de FRADERA foram, para tanto, atores fundamentais.

Durante essa estada, os professores J. LEBULLENGER e C. FLAESCHMOUGIN deram aulas sobre o sistema comercial internacional (OMC) e sobre as relações entre a União Européia e o Mercosul. As professoras M.L. OLIVAR JIMENEZ e Véra Jacob de FRADERA tornaram possíveis, além disso, encontros com diversos universitários de Porto Alegre e com alguns dos juízes da Escola da Magistratura Federal do Estado do Rio Grande do Sul, assim como com seu diretor, o que foi o objetivo prioritário da missão. Contatos no Rio de Janeiro foram igualmente estabelecidos, especialmente com o diretor da Faculdade de Ciências Jurídicas da Universidade do Rio, ASSIS de ALMEIDA.

Desde então, intercâmbios regulares foram mantidos: mobilidade de estudantes (ver quadro final), cooperação científica. O Instituto das Américas foi criado em Rennes (IDA-Rennes, Pólo descentralizado do Instituto das Américas da França) e permitiu reforçar a parceria conferindo-lhe uma dimensão inter-disciplinar. O IDA oferece uma cátedra permitindo acolher professores e pesquisadores das Américas. A Professora Martha L. OLIVAR JIMENEZ esteve em Rennes durante o mês de setembro de 2005 e por quatro dias no mês de janeiro de 2006, nessa qualidade. Participou na "Université Européenne" organizada conjuntamente pelos Pólos de Excelência Jean Monnet de Rennes e de Grenoble. Foi responsável, junto com o Professor JOEL LEBULLENGER do atelier relativo à "Parceria estratégica entre a União Européia e 
a América Latina". As Universidades de Verão permitem acolher estudantes de diferentes continentes. Igualmente a Professora OLIVAR JIMENEZ organizou um seminário de pesquisa, no CEDRE, sobre a evolução jurídica do MERCOSUL.

\section{Objetivos e metas}

\section{Objetivo geral:}

Promover e facilitar o aprofundamento da cooperação entre os dois grupos de pesquisadores dedicados a áreas de conhecimento complementares (direito da Integração Regional e Direito Internacional), garantindo resultados mais eficientes na análise das diferentes questões.

\section{Objetivos Específicos:}

1. Contribuir com a inserção internacional dos programas de pós-graduação de Direito e de Relações Intemacionais da UFRGS mediante a orientação de dissertações de mestrado e teses de doutorado, assim como a realização de co-tutelas e de publicações em conjunto.

2. Organizar eventos científicos para a discussão e aprofundamento das diferentes questões compreendidas no projeto e para permitir a eventual cooperação com pesquisadores de outras universidades brasileiras e do Cone Sul. Tais atividades constituirão um incentivo às atividades de extensão da Faculdade de Direito e do Mestrado de Relações Internacionais.

3. Criação de um banco de dados especializado nas questões relativas à integração européia e latino-americana, assim como o relacionamento internacional dos dois processos perante terceiros Estados e Organizações Internacionais.

4. Contribuir com a formação de especialistas nas áreas de Direito Comunitário, Direito Comercial Internacional, Relações Internacionais, assim como a capacitação de professores de Direito Internacional Público e de Direito da Integração Regional.

5. Incentivar a realização de trabalhos de pesquisa em temas relacionados e a prestação de serviços de consultoria nas questões de Direito Internacional Comercial, particularmente no relativo à solução de conflitos internacionais.

\section{Metodologia e estratégia de ação}

O método escolhido para a obtenção dos resultados é a análise comparativa, sistêmica e teleológica. Ênfase será dada ao estudo do direito das integrações regionais e de suas relações recíprocas. $\mathrm{O}$ estudo do direito gerado do desenvolvimento futuro do acordo de associação será realizado à luz do sistema jurídico da OMC. A reflexão se centrará na comparação e na compatibilidade dos sistemas jurídicos específicos, assim como sobre o grau de convergência de seus fins.

O caráter dominante das ciências juridicas e das relações internacionais justifica a aproximação normativa e jurisprudencial sem deixar de lado o exame da prática nem a análise inter-disciplinar das diferentes questões, principalmente no âmbito do IDA e da parceria com outras universidades e centros de pesquisa brasileiros. 
Fora da execução do plano de trabalho apresentado na primeira parte do projeto, duas atividades específicas são previstas:

A elaboração de uma obra coletiva, com análises comparativas sobre as questões relacionadas aos aspectos institucionais e contenciosos do relacionamento, a ser apresentada ao final do primeiro ano e meio de execução do projeto (julho 2008). Outra publicação, sobre o relacionamento específico dos dois blocos, deveria ser concluída para o período final do projeto (dezembro 2010).

A realização de dois "workshops": um em Porto Alegre organizado no segundo semestre de 2007, com a participação de pesquisadores de outras universidades brasileiras (em particular a Fundação Universitária Ritter dos Reis, a Universidade Federal de Santa Catarina, a FRUB-Universidade Regional de Blumenau, a UNIFRA de Santa Maria, a Universidade Federal de Pelotas) e-do Cone Sul (particularmente a Universidade de Buenos Aires, a Universidade Nacional do Litoral, a Universidade da República - Uruguai). Outro evento seria organizado no primeiro semestre de 2009 em Rennes, com a participação de professores e investigadores do Instituto das Américas - Rennes e do Centro de Excelência Jean Monnet. 